itself provide a full explanation of these phenomena. The present model has the following implications: alterations in neurone A (Fig. 1) occur as the result of the action of the transmitter released from the terminals $E$. These alterations take place as a result of the excitatory input at $\mathrm{E}$, but do not depend on the response of neurone $A$ which may be suppressed by inhibitory inputs at $I$. The alterations in neurone $A$ result in an increase in transmitter release at all its terminals, which may be widely distributed: the potentiation will therefore affect all pathways in which neurone A participates. Finally, although the potentiation is produced by activity in terminals $\mathrm{E}$, any other input which leads to the discharge of neurone A will produce the potentiated response.

I thank Dr H. Blaschko and Sir Bernard Katz for reading my manuscript, and the Medical Research Council for a research grant.

\section{MarianNe Fillenz}

\section{University Laboratory of Physiology,} Oxford

Received January 26, 1972.

${ }^{1}$ Kandel, E. R., and Spencer, W. A., Physiol. Rev., 48, 65 (1968).

${ }^{2}$ Martin, A. R., Physiol. Rev., 46, 51 (1966).

${ }^{3}$ Katz, B., and Miledi, R., J. Physiol., 192, 407 (1967).

- del Castillo, J., and Katz, B., J. Physiol, 124, 553 (1954).

3 Hubbard, J. I., and Kwanbunbumpen, S., J. Physiol, 194, 381 (1968)

B Fillenz, M., and Howe, P. R. C., J. Physiol., 217, 27P (1971).

7 Tranzer, J. P., and Thoenen, H., Experientia, 24, 484 (1968).

${ }^{8}$ del Castillo, J., and Katz, B., J. Physiol. 124, 560 (1954).

- Hubbard, J. I., and Schmidt, R. F., J. Physiol., 166, 145 (1963)

${ }^{10}$ Fillenz, M., and Howe, P. R. C., J. Physiol., 218, 67P (1971).

11 Brown, G. L., Dearnaley, D. P., and Geffen, L. B., Proc. Roy. Soc. B, 168, 48 (1967).

12 Udenfriend, S., Pharmacol. Rev., 18, 43 (1966).

${ }^{13}$ Hörtnagl, M., Hörtnagl, H., and Winkler, H., J. Physiol., 205, 103 (1969).

${ }^{16}$ Mueller, R. A., Thoenen, H., and Axelrod, J., J. Pharmac. Exp. Ther., 169, 74 (1969).

15 Viveros, O. H., Arqueros, L., and Kirschner, N., Mol. Pharmacol., 7, 444 (1971)

${ }^{16}$ Molinoff, P. B., Brimjoin, W. S., Weinshilboum, R. M., and Axelrod, J., Proc. US Nat. Acad. Sci., 66, 453 (1970).

${ }_{17}$ Mueller, R. A., Thoenen, H., and Axelrod, J., Mol. Pharmacol. 5, 463 (1969)

${ }^{18}$ Thoenen, H., Mueller, R. A., and Axelrod, J., Proc. US Nat. Acad. Sci., 65, 58 (1970).

${ }^{19}$ Glassman, E., Ann. Rev. Biochem., 38, 605 (1969).

${ }^{20}$ Gisiger, V., Brain Res., 33, 139 (1971).

\section{Alpha Rhythms and Hyperkinesis}

IN his report "Alpha Rhythms in the Hyperkinetic Child"', Shetty attempts to define the neurophysiological substrate of hyperkinesis by interpreting drug-induced variations in the alpha rhythms of the human electroencephalogram (EEG). Such an attempt presumes knowledge of the origin of alpha rhythms, but the single article ${ }^{2}$ to which Shetty refers, and which is said to allege that "alpha rhythms represent an inhibitory process involving discharge of sub-cortical influences back into the cortex, and effecting the termination of cortical excitation associated with autornatization or habituation of learned behaviour", in fact contains no evidence on such physiological processes. It refers in turn to an earlier physiological observation-the so-called "recruiting response" in cats $^{3}$, which may or may not have any connexion with human alpha rhythms.

Some controversy surrounds the origin of alpha rhythms. Mulholland and Evans ${ }^{4-6}$ have demonstrated that the presence or absence of alpha rhythms is determined not by the presence or absence of relaxed wakefulness but by oculomotor function. Complementary observations by Lippold ${ }^{7,8}$ suggest that both physiological tremor and alpha rhythms in the EEG reflect oscillations in striate muscle control systems.
Some of the earliest physiological observations on alpha rhythms show a significant relationship between metabolic rate and alpha rhythm voltage?. In particular hypothyroidism, and the accompanying reduction in physiological tremor, has been known for many years to be associated with a reduction in the amplitude of alpha rhythms ${ }^{10}$. It is therefore unfortunate that Shetty did not make a comparison both of alpha rhythm characteristics and physiological tremor in normal and hyperkinetic children. The only conclusions which can reasonably be drawn are that central nervous stimulants such as amphetamines, which are well known to increase the magnitude of physiological tremor ${ }^{11}$, also increase the alpha rhythm power range. This provides no direct information concerning the neurophysiological substrate of hyperkinesis although it does support Lippold's hypothesis that oscillation in striate muscle control systems is the source of alpha rhythm and that a tendency for overall change in muscle control systems will be paralleled by changes in the alpha signal.

\section{N. Davidson}

Department of Physiology,

Marischal College,

University of Aberdeen,

Aberdeen

Received January 10; revised February 19, 1972.

1 Shetty, T., Nature, 234, 476 (1971).

2 Darrow, C. W., Veith, R. N., and Wilson, J., Science, 126, 74 (1957).

3 Dempsey, E. W., and Morison, R. S., Amer. J. Physiol., 135, 293 (1942).

${ }^{4}$ Mulholland, T. B., and Evans, C. R., Nature, 207, 36 (1965).

5 Mulholland, T. B., and Evans, C. R., Nature, 211, 1278 (1966).

${ }^{6}$ Mulholland, T. B., in Attention in Neurophysiology (edit. by Evans, C. R., and Mulholland, T. B.) (Butterworths, London, 1969).

7 Lippold, O. C. J., and Novotny, G. E. K., J. Physiol., 194, 28P (1968).

${ }^{8}$ Lippold, O. C. J., Redfearn, J. W. T., and Vuco, J., J. Physiol., 137,473 (1957).

9 Lindsley, D. B., and Rubenstein, B. B., Proc. Soc. Exp. Biol., 35, 558 (1937).

10 Bertrand, I., Delcy, J., and Guillain, J., CR Soc. Biol., 129, 395 (1938).

11 Goodman, L. S., and Gillman, A., in The Pharmacological Basis of Therapeutics, third ed. (Collier-Macmillan, London, 1965).

\section{Alpha Rhythms in the Hyperkinetic Child}

BECAUSE of my misunderstanding about certain technical aspects of the research which I reported recently ${ }^{1}$ I would like to make the following clarifications.

The magnetic tape recordings from which the $r$ values of Table 1 were computed were obtained under two different filter settings. Eight electroencephalograms (six patients and two controls) were recorded on f.m. tape with 10 cycle low pass filter (Grass model $78 \mathrm{EEG}$ recorder), whereas nine (six patients and three controls) were recorded with 1 cycle filter. Data from twelve subjects and all the five controls were collected directly on f.m. tape. Data from sixteen patients were transferred to f.m. tape from ink writing charts for purposes of analogue to digital conversion necessary to frequency analysis. This transfer was performed by an automatic curve reader. But because of the high paper speed to the reader, considerable attenuation of high frequency components of the electroencephalogram existed in this group. Only the alpha band was selected for the analysis because this band was least affected by these manoeuvres. Moreover, the effect on alpha band was remarkable on inspection of the electroencephalogram record obtained on paper in at least one patient, and this was another reason for limiting the analysis to alpha frequencies. Thus, this band is the most sensitive, but might not be the only one which was sensitive 